\title{
Assessment of motivation to control alcohol use: The motivational thought frequency and state motivation scales for alcohol control
}

Robinson, $\mathrm{N}$

http://hdl.handle.net/10026.1/4521

10.1016/j.addbeh.2016.02.038

Addictive Behaviors

Elsevier BV

All content in PEARL is protected by copyright law. Author manuscripts are made available in accordance with publisher policies. Please cite only the published version using the details provided on the item record or document. In the absence of an open licence (e.g. Creative Commons), permissions for further reuse of content should be sought from the publisher or author. 
Assessment of Motivation to Control Alcohol Use: The Motivational Thought Frequency and State Motivation Scales for Alcohol

Nicole Robinson, David Kavanagh

Institute of Health \& Biomedical Innovation, School of Psychology \& Counselling, and Centre for Children's Health Research, Queensland University of Technology (QUT)

\section{Jason Connor}

Centre for Youth Substance Abuse, Discipline of Psychiatry, School of Medicine, University of Queensland

Jon May and Jackie Andrade

School of Psychology, Cognition Institute, Plymouth University

Address for correspondence: Professor David Kavanagh, Level 6, Centre for Children's Health Research, 62 Raymond Terrace, South Brisbane, Qld 4101 Australia

david.kavanagh@qut.edu.au

246/250 Abstract

$3126 / 3500$ Text
Authors' accepted post-referee manuscript Robinson, N., Kavanagh, D.J., Connor, J., May, J. \& Andrade, J. (2016). Assessment of motivation to control alcohol use: the motivational thought frequency and state motivation scales for alcohol. Addictive Behaviors.

(C)2016 This manuscript version is made available under the CC-BY-NC-ND 4.0 license, http://creativecommons.org/licenses/by-nc-nd/4.0/ 


\begin{abstract}
Introduction: The Elaborated Intrusion Theory of Desire holds that desires for functional and dysfunctional goals share a common form. Both are embodied cognitive events, characterised by affective intensity and frequency. Accordingly, we developed scales to measure motivational cognitions for functional goals (Motivational Thought Frequency, MTF; State Motivation, SM), based on the existing Craving Experience Questionnaire (CEQ). When applied to increasing exercise, MTF and SM showed the same three-factor structure as the CEQ (Intensity, Imagery, Availability). The current study tested the internal structure and concurrent validity of the MTF and SM Scales when applied to control of alcohol consumption (MTF-A; SM-A).
\end{abstract}

Methods: Participants $(N=417)$ were adult tertiary students, staff or community members who had recently engaged in high-risk drinking or were currently trying to control alcohol consumption. They completed an online survey comprising the MTF-A, SM-A, Alcohol Use Disorders Identification Test (AUDIT), Readiness to Change Questionnaire (RCQ) and demographics.

Results: Confirmatory Factor Analysis gave acceptable fit forthe MTF-A, but required the loss of one SM-A item, and was improved by intercorrelations of error terms. Higher scores were associated with more severe problems on the AUDIT and with higher Contemplation and Action scores on the RCQ.

Conclusions: The MTF-A and SM-A show potential as measures of motivation to control drinking. Future research will examine their predictive validity and sensitivity to change. The scales' application to both increasing functional and decreasing dysfunctional behaviours is consistent with EI Theory's contention that both goal types operate in similar ways. Keywords: High-Risk Alcohol Use, Assessment, Motivation, Desire, Confirmatory Factor Analysis. 


\section{Introduction}

Goals and desires are intimately related. Valued goals that motivate an individual's behaviour are intrinsically desired (Fishbach, Shah, \& Kruglanski, 2004), and desires mediate the relationship of attitudes, perceived norms and behavioural control, with intentions to achieve a goal (Perugini \& Bagozzi, 2001). Desires form a critical component in motivation to reach functional goals, but can also trigger dysfunctional behaviours, as in the case of strong desires or cravings for drug use.

In Elaborated Intrusion theory (EI theory; Kavanagh, Andrade \& May, 2005; May, Kavanagh \& Andrade, 2015a), functional and dysfunctional desires are affectively-charged cognitive events that vary in frequency and strength (Kavanagh, Statham et al., 2012). While their precursors are often unconsciously and automatically triggered (e.g. cognitive associations or conditioned external cues), desires are conscious experiences. In fact, we argue that desires are effective at guiding behaviour only to the extent that they are in conscious attention at key decision points (e.g. when deciding whether to have a drink) or have historically elicited behaviours favouring control or consumption sufficiently frequently for them to become habitual (e.g. a travel route passing an alcohol outlet). In consequence, capturing their current or strongest recent intensity and their frequency is likely to be critical to the measurement of treatment outcomes and prediction of lapses in control.

Most current measures of functional motivations such as control of alcohol use do not directly capture these key characteristics, but instead focus on their determinants or effects. For example, tools based on the Transtheoretical Model of Prochaska and DiClimente (1983) such as the Readiness to Change Questionnaire (Heather \& Rollnick, 1993) assess agreement with attitudes towards alcohol use (e.g. "I don't think I drink too much") and related issues (e.g. "My drinking is a problem sometimes"), and may describe a current action (e.g. "I am actually changing my drinking habits right now") or goal (e.g. "I am trying to drink less than 
I used to"), but they do not assess how often the goal is in focal attention, or how intense the affective investment is in the goal. Other measures such as the Motivation for Change Questionnaire (de Jonge, Barelds, Schippers, \& Schaap, 2009) also include other constructs that are relevant to motivation (e.g. self-efficacy, incentives promoting or impeding change), but mix these with attitudes or intentions. De Jonge et al. (2009) also used a single-item rating of current motivational strength, but such assessments are psychometrically inferior to multi-item scales.

EI Theory also suggests types of motivational cognitions that may be especially important to assess. As the name of the theory suggests, desires for a goal can be triggered by associative processes, where the cognition is initially experienced as an intrusive thought or image. The anticipatory pleasure that is linked to that cognition elicits its further elaboration in working memory. That process also continues to activate associations, which aid in keeping related cognitions available. A substantial body of research now supports the contention that highly motivational cognitions are typically embodied, involving vivid multisensory imagery (May et al., 2015a). So, assessments of motivational cognitions should incorporate imagery and capture the availability of associations that trigger and maintain it.

A psychometric measure of desire or craving to drink (the Alcohol Craving Experience Questionnaire, ACE; Statham et al., 2011), which meets all of these criteria, has already been developed. The ACE comprises two scales: ACE-Strength measures either current craving, or peak craving over a specified period, while ACE-Frequency assesses the frequency of alcohol cravings over that period. Exploratory and confirmatory factor analyses revealed a clear three-factor structure of Intensity, Imagery and Intrusion for both scales, which also demonstrated discriminant and concurrent validity (Statham et al., 2011). Subsequently, the ACE was generalised to a range of appetitive substances or activities, to 
form the Craving Experience Questionnaire (CEQ; May et al., 2014). The CEQ demonstrated the same internal structure using a confirmatory factor analysis (CFA) that was performed using a heterogeneous sample of 1230 participants from 12 studies. Its internal structure and convergent validity were maintained over different timescales and across desires for alcohol, cigarettes, chocolate and other food (May et al., 2014).

Both the ACE and the CEQ address appetitive desires, but the original account of EI Theory is clear that appetitive desires operate in the same way as other motivational thoughts, including those that support engaging in functional goals or avoiding dysfunctional goals, often the focus of behaviour change interventions. The strong properties of the ACE and CEQ provided a stable psychometric foundation for the creation of conceptually coherent scales to measure both the frequency of desires for behaviour change (Motivational Thought Frequency, MTF, modelled on the Frequency form of the ACE and CEQ) and the strength of those desires (State Motivation, SM, modelled on their Strength form). In developing these scales, items from the ACE and CEQ have been adapted to focus on a functional behavioural goal rather than an appetitive target. Little change was required to Intensity items (want, need, strong urge), but Imagery items now focused on foci for functional change (e.g. "imagine yourself doing it"; "imagine how good it would be"; "imagine succeeding at it") rather than specific senses (e.g. picture, taste, smell). These images are assumed to be multisensory, as with other desire images, but the altered focus of the questions reflects our assumption (Kavanagh et al., 2014) that effective motivation requires imagery that embodies positive affective charge, pathways to the goal and self-efficacy. Items on Intrusions (e.g. "how hard were you trying not to think about alcohol?"; "how intrusive were the thoughts?") became "How much are other things reminding you about it?"; "How much are thoughts about it grabbing your attention?"; "How easily can you keep it in mind?", and the subscale was renamed Availability to better reflect the more welcome nature of these cognitions. 
The CEQ and ACE Strength focused on the maximum desire in a specified time period (e.g. over the last week), because the person may not be actively craving alcohol at assessment. In contrast, SM focuses on the person's current state of motivation, in order to capture present motivational state (e.g. during a session).

Confirmatory factor analyses on the MTF and SM to increase physical exercise (MTFE, SM-E; Kavanagh et al., in Submission) have demonstrated that both 12-item scales have the same three-factor internal structure (Intensity -3 items, Imagery — 6 items, Availability3 items) as the ACE and CEQ. This structure was superior to both a single-factor model and to models that conflated two of the three factors. The scales also showed strong concurrent validity against another measure of motivational imagery for physical activity, the Exercise Imagery Inventory (Giacobbi, Tuccitto, Buman, \& Munroe-Chandler, 2010).

The current study examined the psychometric properties of an adaptation of the MTF and SM to control of alcohol consumption (MTF-A; SM-A). To our knowledge, these scales constitute the first direct measures of motivational cognitions about controlling alcohol consumption. This study examined whether the scales would exhibit a similar three-factor structure as MTF-E, SM-E, ACE and CEQ, providing a further test of an important tenet of EI theory, that similar cognitive processes underpin desires for functional as well as dysfunctional goals. To aid in rapid acquisition of an initial sample, we used online recruitment and data collection. We expected that greater motivation to address alcohol use would be seen in people who were contemplating or acting on change, than in those who were not considering change. Greater motivation to change was also expected in people who self-reported more alcohol-related problems. 


\section{Method}

\section{Participants}

Prospective participants were invited to participate in the study through group emails to staff and student cohorts and affiliated research groups from Queensland University of Technology, and advertisements on social media or networking websites. Eligibility criteria were: $\geq 18$ years of age, and reporting alcohol consumption above Australian guidelines for risk of injury on a single occasion in the previous month (i.e. $>4$ drinks of $10 \mathrm{gm}$ ethanol; (National Health and Medical Research Council, 2009), or currently trying to control their drinking. To avoid missing data imputation in the confirmatory factor analyses (allowing modification indices to be created), included participants had to complete, at least, the MTFA or SM-A without missing items.

\section{Materials}

The Motivational Thought Frequency for Alcohol Control (MTF-A) and State Motivation for Alcohol Control (SM-A) scales were identical to the equivalent scales on physical exercise (SM-E; MTF-E; Kavanagh et al., in submission), except that their initial instruction read: "Thinking about cutting down or stopping drinking..." rather than "Thinking about increasing your physical activity...". The 12 MTF-A items were preceded by "Over the last week, how often did you...", followed by, for example, “... feel you wanted to do it?". Ratings were in integers from 0 - Never, to 10 - Constantly. The 12 SM-A items were preceded by "Right now...", followed by, for example, “...how strongly do you want to do it?", and were rated in integers from 0 -Not at all, to 10 -Extremely. Items of both scales are reproduced in Table 2. The Alcohol Use Disorders Identification Test (AUDIT; Saunders, Aasland, Babor, De La Fuente, \& Grant, 1993; World Health Organisation, 2001) is a 10 -item scale to screen for alcohol problems. Total scores range from $0-40$, and a total $\geq 8$ indicates the possible presence of an alcohol disorder. The AUDIT has sound validity and 
internal consistency, even when used in different settings and populations (Reinert \& Allen, 2007).

The Readiness to Change Questionnaire (RCQ; Heather \& Rollnick, 1992, 1993) is designed to identify an individual's readiness to control their alcohol use. The 12-item scale has three subscales corresponding to stages of change (Precontemplation, Contemplation, Action; Heather \& Rollnick, 1993; Prochaska \& DiClemente, 1983). The RCQ can be used to classify an individual into a stage, using the highest subscale score (Rollnick, Heather, Gold, \& Hall, 1992). The RCQ has sound psychometric properties, including acceptable internal consistency, test-retest reliability and predictive validity over time (Heather \& Rollnick, 1993; Heather, Rollnick, \& Bell, 1993; Rollnick et al., 1992).

\section{Procedure}

Ethical approval was granted from the Queensland University of Technology Human Research Ethics Committee (\# 1400000385). Consent and data collection were online via SurveyMonkey ${ }^{\mathrm{TM}}$. Prospective participants who did not meet inclusion criteria were told the reason for their ineligibility and given contact details of the research team for any questions. The survey comprised the demographic questionnaire, SM-A, MTF-A, RCQ and AUDIT (in that order). After completing the survey, all participants were given information about highrisk levels of alcohol use and contact details for services. Participants from introductory psychology classes were provided with course credits, while others were invited to enter a prize draw for a chance to win a tablet device. Identification details (emails, codes for course credit) were stored separately from survey responses and destroyed at the end of data collection. Data were therefore identifiable at collection, but were anonymised for analysis.

\section{Confirmatory Factor Analyses}

A three-factor non-hierarchically nested model was posited a priori with the emergence of 'Intensity', 'Imagery' and 'Availability' predicted based on previous 
Confirmatory Factor Analyses (CFAs) on the ACE, CEQ (May et al., 2014) and MTF-E (Kavanagh et al., in submission). Competing theoretical models examined the possible presence of either a single or two-factor structure, involving two of the three factors coalescing (Jackson, Gillaspy, \& Purc-Stephenson, 2009).

The CFAs were conducted using SPSS AMOS Version 22. We used Maximum Likelihood (ML) estimation, which assumes the assumption of multivariate normality (Jackson et al., 2009). Model fit was evaluated using a lower Akaike's Information Criterion (AIC), $\chi^{2} / \mathrm{df}$, Standardised Root Mean Square (SRMR) and Root Mean Square Error of Approximation (RMSEA), and by a greater Bentler's Comparative Fit Index (CFI), Bollen's Relative Fit Index (RFI) and Incremental Fit Index (IFI), and Tucker-Lewis Index (TLI). Good fit was defined by CFI, RFI, IFI and TLI $>0.90$, and SRMR $<0.08$, with acceptable fit involving results approaching these criteria. RMSEA is prone to variable results in moderate sized samples, rendering the use of specific cutoffs problematic (Chen, Curren, Bollen, Kirby, \& Paxton, 2008), but a result $<.10$ was regarded as indicative of good fit. Any item elimination or intercorrelation of error terms was based on modification indices. Intercorrelations of errors were only allowed between ones within the same factor.

\section{Results}

\section{Participants}

A total of 504 people consented to complete the survey. Three failed to confirm that they were 18 or over, and another 25 did not confirm that they met the alcohol consumption or reduction criteria. Of the 476 remaining, 417 (88\%) also fully completed the MTF-A and SM-A. This sample was predominantly female $(61 \%, n=254)$, and was aged 27.7 years on average $(\mathrm{SD}=9.3$, Range $=18-61)$. Most $(80 \%, \mathrm{n}=335)$ had completed or were undertaking university studies. They had an average AUDIT of $10.9(\mathrm{SD}=6.0$, Range $=2-31)$, and $64 \%$ 
(244) screened positive for an alcohol use disorder ( $\geq 8)$. Of those completing the RCQ, 167 (40\%) were in Precontemplation, 128 (31\%) in Contemplation, and 62 (15\%) in Action.

$$
\overline{\text { Insert Table } 1 \text { about here }}
$$

\title{
Confirmatory Factor Analyses
}

$M T F-A$. The hypothesised three-factor model was statistically superior to the singlefactor and factor models that combined two of the three factors (Table 1). CFI, NFI, RFI, IFI and TLI were all $>0.90$, and SRMR was well below $<0.08$. While RMSEA was slightly greater than .10 and the adjusted chi-square was higher than ideal, in the context of the other excellent results and recent criticism of RMSEA (Chen et al., 2008), the fit was considered acceptable. Modification indices suggested that two pairs of error terms from the Imagery factor should be intercorrelated (Table 1). When this intercorrelation was included in the model, all indices clearly indicated acceptable fit or better. Factor score weights are shown in Table 2.

$S M-A$. Once again, the hypothesised three-factor model was superior to the singlefactor and two-factor models (Table 1). However, the three-factor model still fell short of good fit. Inspection of the modification indices suggested the omission of the item, "How easily can you keep it in mind". With that item removed, AIC improved substantially and the fit became acceptable on all indices except RFI (just short of .90), RMSEA and the adjusted chi-square. If the error terms from two pairs of Imagery items were allowed to intercorrelate, RMSEA and the adjusted chi-square remained high, but other indices suggested good fit. The resultant factor score weights are in Table 2.

\author{
Insert Tables 2 and 3 about here
}




\section{Internal consistency}

Table 3 displays the internal consistencies and ranges of corrected item-total correlations for the final MTF-A and SM-A subscales, which were all high. Even though a single-factor model did not provide good fit to the data, the internal consistency of the total scores was also high.

\section{Relationship with RCQ and AUDIT}

As expected, higher SM-A scores were seen in participants with more severe alcoholrelated problems (as indexed by higher AUDIT scores), and in those whose RCQ Contemplation and Action scores were high, while Precontemplation scores were inversely related to the SM-A. We also examined the relationship in terms of mean SM-A scores in different RCQ groups: as shown in Table 3, these also showed highly significant differences, with participants in Precontemplation having MTF-A and SM-A scores below those for participants in Contemplation or Action.

\section{Discussion}

Confirmatory factor analyses on the MTF-A and SM-A exhibited the same internal structure as the MTF-E and SM-E (Kavanagh et al., in submission), and confirmed that the structure also matched that previously obtained in craving measures for alcohol and other appetitive targets (ACE, Statham et al., 2011; CEQ, May et al., 2014). All these measures provide information on frequency strength of desires, as well as separate factors on desire imagery and availability of desire cognitions. The results support the use of the MTF and SM for both increasing a desired behaviour such as physical exercise, and reducing a problematic one. The expected relationships of the MTF-A and SM-A with both readiness to change and degree of self-perceived alcohol problems provide strong evidence of concurrent validity. Furthermore, the fact that all subscales offered substantial correlations with the RCQ and AUDIT was highly consistent with EI Theory's contentions that the intensity, availability and 
imagery content of motivational cognitions are critical to their power, and that both their current state and frequency are important to assess. When considered together, the body of data from the ACE, CEQ and these new motivational scales supports our view that desires for both beneficial and potentially harmful goals have the same form.

Consistent with the initial paper on the MTF and SM for exercise (Kavanagh et al., in submission), a 3-factor model gave acceptable fit on MTF-A even without the correlation of error terms that was required to obtain good fit on SM-A. Also consistent with the initial paper was that RMSEA was above the frequently used level of .05 for good fit, although in the earlier paper it was below .10 for both scales. In fact, good fit for the SM-A was only obtained in the current study after the omission of the item, "How easily can you keep it in mind". That item was less consistent with the current-state focus than the other SM items, and addressed a different phenomenon from its MTF equivalent ("How often did thoughts about it come to mind?"). Its removal can be seen as improving the theoretical coherence of the SM scale, but left it with only two items, which is not ideal. While this item was positively skewed $(.526, \mathrm{SE}=$ .120 ), with $29 \%$ respondents scoring zero, so were most other items (Median skewness $=.517$; Median of $28 \%$ scoring zero). A check of the obtained model and of the contribution of this item in a sample with moderate to severe alcohol use disorder, including participants who were seeking treatment, is therefore recommended. Further research should also establish the sensitivity of the MTF-A and SM-A to treatment-induced changes, and their ability to predict engagement and maintenance of an attempt to control alcohol use. We predict that the SM-A scale may prove useful as a measure of acute changes after sessions of interventions such as motivational interviewing (Miller \& Rollnick, 2002; Rubak, Sandbaek, Lauritzen, \& Christensen, 2005), and that it will be especially sensitive to proximal effects of Functional Imagery Training, a new treatment based on Elaborated Intrusion Theory that focuses on strengthening desire imagery (Kavanagh, Andrade, May, \& Connor, 2014; May, Andrade, \& 
Kavanagh, 2015b). In contrast, we expect that MTF-A scale will be a better predictor of control of alcohol consumption, especially over the following few days.

Limitations to the current study include a potential threat to sample representativeness from the unknown response rate of the online survey, and an over-representation of females, young adults and university-educated participants. Online administration of the survey also precludes a check on the degree that respondents were genuinely engaged in the task. Confirmation of the current results in a gender-balanced sample with a wider range of age and socioeconomic backgrounds and in samples with more established alcohol use disorder is therefore recommended. However, the young cohort that we used provided an important focus, as a group that is particularly susceptible to high-risk alcohol use (Australian Institute of Health and Welfare, 2011), and the sample did contain a substantial proportion that screened positive for alcohol use disorder.

\section{Conclusion}

Initial testing of the Motivational Thought Frequency and State Motivation scales for Alcohol suggests that they may have significant potential as a measure of the strength and frequency of motivational cognitions about addressing alcohol misuse. If their early promise is confirmed in studies of their sensitivity to change and their discriminant and predictive validity, they will offer an important assessment tool for clinical research and practice. 


\section{References}

Andrade, J., Pears, S., May, J. \& Kavanagh, D. J. (2012). Use of a clay modeling task to reduce chocolate craving, Appetite, 58, 955-963. doi: 10.1016/j.appet.2012.02.044 Australian Institute of Health and Welfare (2011). 2010 National Drug Strategy Household Survey report. Retrieved from http://www.aihw.gov.au/WorkArea/DownloadAsset.aspx?id=10737421314

Chen, F., Curren, P. J., Bollen, K. A., Kirby J., \& Paxton, P. (2008). An empirical evaluation of the use of fixed cutoff points in RMSEA test statistic in structural equation models. Sociological Methods Research, 36, 462-494. doi: 10.1177/0049124108314720

de Jonge, J. M., Barelds, D. P., Schippers, G. M., \& Schaap, C. P. (2009). Motivation to change drinking habits: development of a new instrument. Netherlands Journal of Psychology, 65, 102-111. doi: 10.1007/BF03080132

Fishbach, A., Shah, J. Y., \& Kruglanski, A. W. (2004). Emotional transfer in goal systems. Journal of Experimental Social Psychology, 40, 723-738. doi:10.1016/j.jesp.2004.04.001

Giacobbi, P. R., Tuccitto, D. E., Buman, M. P., \& Munroe-Chandler, K. (2010). A measurement and conceptual investigation of exercise imagery establishing construct validity. Research Quarterly for Exercise and Sport, 81, 485-493. doi: $10.1080 / 02701367.2010 .10599710$

Heather, N., \& Rollnick, S. (1993). Readiness to Change Questionnaire: User's Manual (Revised Version): National Drug and Alcohol Research Centre, University of New South Wales.

Heather, N., Rollnick, S., \& Bell, A. (1993). Predictive validity of the Readiness to Change Questionnaire. Addiction (Abingdon, England), 88, 1667-1677. doi: 10.1111/j.13600443.1993.tb02042.x 
Jackson, D. L., Gillaspy, J. A., \& Purc-Stephenson, R. (2009). Reporting practices in confirmatory factor analysis: An overview and some recommendations. Psychological Methods, 14, 6-23. doi: 10.1037/a0014694

Kavanagh, D., Connolly, J. M., May, J., Andrade, J., Godfrey, S., Carroll, A., . . Connor, J. P. (In Submission). The Motivational Thought Frequency scale for Exercise (MTF-E): A new measure of motivational cognition.

Kavanagh, D. J., Andrade, J., \& May, J. (2005). Imaginary relish and exquisite torture: The Elaborated Intrusion Theory of Desire. Psychological Review, 112(2), 446-467. doi: $10.1037 / 0033-295 x .112 .2 .446$

Kavanagh, D. J., Andrade, J., May, J., \& Connor, J. (2014). Motivational interventions may have greater sustained impact if they trained imagery-based self-management. Addiction, 109, 1062-1063. doi: 10.1111/add.12507

Kavanagh, D. J., Statham, D. J., Feeney, G. F. X., Young, R. M., May, J., Andrade, J., \& Connor, J. P. (2013). Measurement of alcohol craving. Addictive Behaviors, 38(2), 1572-1584. doi: 10.1016/j.addbeh.2012.08.004

May, J., Kavanagh, D. J., \& Andrade, J. (2015a). The Elaborated Intrusion Theory of Desire: A 10-year retrospective and implications for addiction treatments. Addictive Behaviors, 44, 29-34. doi: 10.1016/j.addbeh.2014.09.016

May, J., Andrade, J., \& Kavanagh, D. J. (2015b). An imagery-based road map to tackle maladaptive motivation in clinical disorders. Frontiers in Psychiatry, 6, 14. doi: 10.3389/fpsyt.2015.00014

May, J., Andrade, J., Kavanagh, D. J., Feeney, G. F. X., Gullo, M. J., Statham, D. J., . . Connor, J. P. (2014). The Craving Experience Questionnaire: A brief, theory-based measure of consummatory desire and craving. Addiction, 109, 728-735. doi: 10.1111/add. 12472 
May, J., Andrade, J., Willoughby, K., \& Brown, C. (2011). An attentional control task reduces intrusive thoughts about smoking. Nicotine \& Tobacco Research, 14, 472478. doi: $10.1093 / \mathrm{ntr} / \mathrm{ntr} 238$.

Miller, W., \& Rollnick, S. (2002). Motivational interviewing: Preparing people for change (2nd ed.). New York: Guilford Press.

National Health and Medical Research Council. (2009). Australian Guidelines to Reduce Health Risks from Drinking Alcohol. Retrieved from https://www.nhmrc.gov.au/_files_nhmrc/publications/attachments/ds10-alcohol.pdf

Perugini, M., \& Bagozzi, R. P. (2001). The role of desires and anticipated emotions in goaldirected behaviours: Broadening and deepening the theory of planned behaviour, British Journal of Social Psychology, 40, 79-98. doi: 10.1348/014466601164704

Prochaska, J. O., \& DiClemente, C. C. (1983). Stages and processes of self-change of smoking: Toward an integrative model of change. Journal of Consulting and Clinical Psychology, 51, 390-395. doi: 10.1037/0022-006X.51.3.390

Reinert, D. F., \& Allen, J. P. (2007). The Alcohol Use Disorders Identification Test: An update of research findings. Alcoholism: Clinical \& Experimental Research, 31, 185199. doi: 10.1111/j.1530-0277.2006.00295.x

Rollnick, S., Heather, N., Gold, R., \& Hall, W. (1992). Development of a short 'readiness to change' questionnaire for use in brief, opportunistic interventions among excessive drinkers. British Journal of Addiction, 87, 743-754. doi: 10.1111/j.13600443.1992.tb02720.x

Rubak, S., Sandbaek, A., Lauritzen, T., \& Christensen, B. (2005). Motivational interviewing: a systematic review and meta-analysis. The British Journal of General Practice, 55(513), 305-312. 
Saunders, J. B., Aasland, O. G., Babor, T. F., De La Fuente, J. R., \& Grant, M. (1993). Development of the Alcohol Use Disorders Identification Test (AUDIT): WHO collaborative project on early detection of persons with harmful alcohol consumption-II. Addiction, 88, 791-804. doi: 10.1111/j.1360-0443.1993.tb02093.x

Statham, D. J., Connor, J. P., Kavanagh, D. J., Feeney, G. F. X., Young, R. M. D., May, J., \& Andrade, J. (2011). Measuring alcohol craving: Development of the Alcohol Craving Experience questionnaire. Addiction, 106, 1230-1238. doi: 10.1111/j.13600443.2011.03442.x

World Health Organisation. (2001). The Alcohol Use Disorders Identification Test: Guidelines for Use in Primary Care. Second Edition. Retrieved from http://whqlibdoc.who.int/hq/2001/who_msd_msb_01.6a.pdf 
Table 1. Confirmatory Factor Analyses on the Motivational Cognition Frequency (MTF-A) and State Motivation (SM-A) Scale for Alcohol

\begin{tabular}{|c|c|c|c|c|c|c|c|c|c|}
\hline & $\chi^{2} / \mathrm{df}$ & CFI & NFI & RFI & IFI & TLI & SRMR & RMSEA & $\mathrm{AIC}$ \\
\hline \multicolumn{10}{|l|}{ MTF-A } \\
\hline 1 factor & 15.82 & .875 & .867 & .838 & .875 & .847 & .041 & .196 & 902.28 \\
\hline 2 factors (Intensity/Imagery, Availability) & 12.02 & .908 & .901 & .877 & .909 & .886 & .033 & .169 & 687.00 \\
\hline 2 factors (Intensity/Availability, Imagery) & 11.02 & .917 & .909 & .887 & .917 & .896 & .038 & .161 & 634.00 \\
\hline 3 Factors & 5.11 & .967 & .960 & .948 & .967 & .957 & .024 & .103 & 314.47 \\
\hline 3 factors, correlating error terms ${ }^{1}$ & 3.66 & .980 & .972 & .963 & .980 & .972 & .019 & .083 & 237.22 \\
\hline \multicolumn{10}{|l|}{ SM-A } \\
\hline 1 factor & 24.26 & .702 & .694 & .625 & .702 & .635 & .113 & .236 & 1357.92 \\
\hline 2 factors (Intensity/Imagery, Availability) & 19.27 & .770 & .761 & .702 & .771 & .713 & .125 & .210 & 1071.33 \\
\hline 2 factors (Intensity/Availability, Imagery) & 14.60 & .829 & .819 & .775 & .829 & .787 & .103 & .181 & 823.86 \\
\hline 3 Factors & 8.52 & 909 & .898 & .868 & .909 & .882 & .109 & .134 & 488.41 \\
\hline $\begin{array}{l}3 \text { factors, } 11 \text { items, omitting 'How easily } \\
\text { can you keep it in mind' }\end{array}$ & 7.69 & .930 & .921 & .893 & .930 & .906 & .080 & .127 & 365.18 \\
\hline 3 factors, 11 items, correlating error terms ${ }^{2}$ & 6.19 & .948 & .939 & .914 & .949 & .927 & .082 & .112 & 295.22 \\
\hline
\end{tabular}

1. '...imagine succeeding at it' with '...picture times you did something like this in the past'; '...imagine yourself doing it' with '...imagine how you would do it.'

2. '...imagine how much worse you'll feel if you don't do it' with '....imagine how good it would be to do it' and with '...imagine how you would do it.' 
Table 2. Factor Score Weights from the Final Model in Confirmatory Factor Analyses

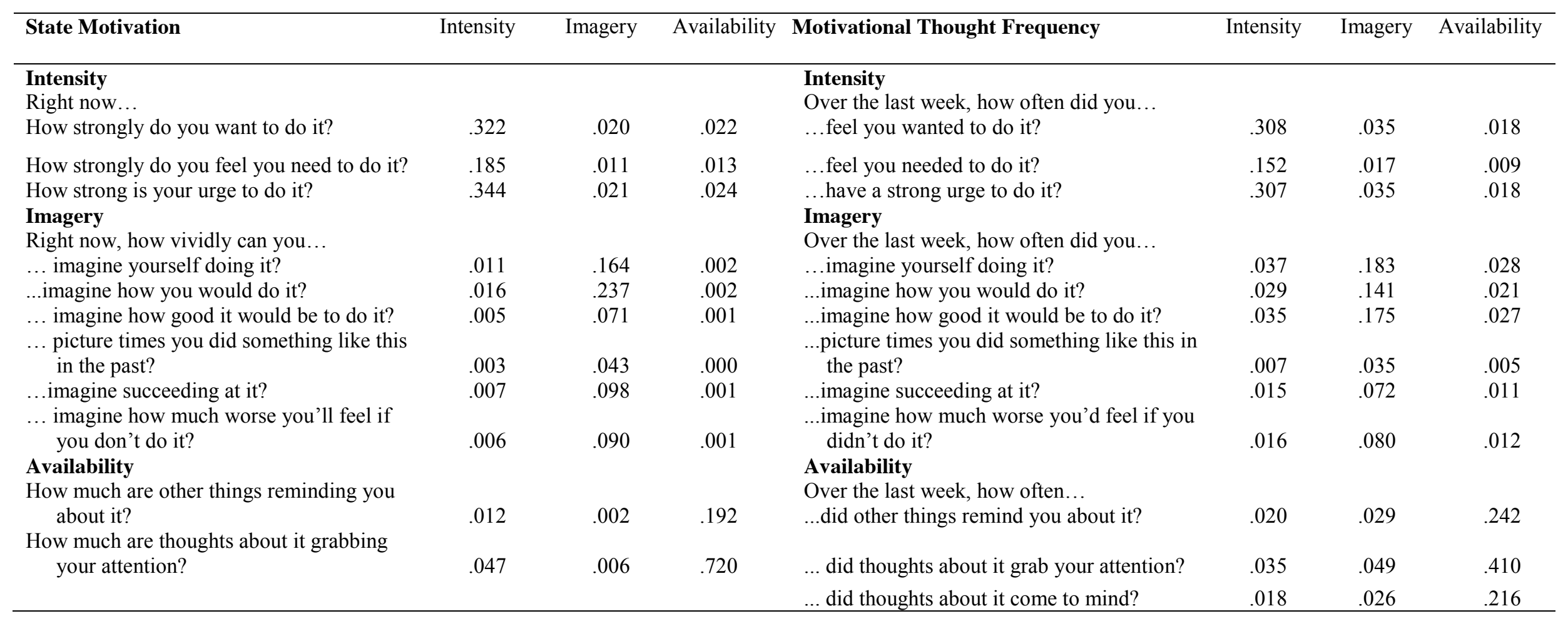


Table 3. Internal consistency of the MTF-A and SM-A Scales and intercorrelations with the Readiness to Change Questionnaire (RCQ) and Alcohol Use Disorders Identification Test (AUDIT)

\begin{tabular}{|c|c|c|c|c|c|c|c|c|c|}
\hline & \multirow{2}{*}{$\begin{array}{l}\text { Coefficient alpha } \\
\text { (Corrected item- } \\
\text { total correlations) }\end{array}$} & \multirow[t]{2}{*}{$\begin{array}{c}\text { AUDIT }^{1} \\
r\end{array}$} & \multicolumn{3}{|c|}{$\begin{array}{c}\text { RCQ subscale scores }^{1} \\
r\end{array}$} & \multicolumn{3}{|c|}{$\begin{array}{c}\text { RCQ Classifications } \\
\text { GMSAF and GMAS Mean (SD) }\end{array}$} & \multirow[b]{2}{*}{$F(2,354)$} \\
\hline & & & $\begin{array}{l}\text { Precontemplation } \\
(\mathrm{n}=167)\end{array}$ & $\begin{array}{l}\text { Contemplation } \\
(\mathrm{n}=128)\end{array}$ & $\begin{array}{l}\text { Action } \\
(\mathrm{n}=62)\end{array}$ & $\begin{array}{l}\text { Precontemplation } \\
(\mathrm{n}=167)\end{array}$ & $\begin{array}{l}\text { Contemplation } \\
(\mathrm{n}=128)\end{array}$ & $\begin{array}{l}\text { Action } \\
(\mathrm{n}=62)\end{array}$ & \\
\hline \multicolumn{10}{|l|}{ MTF-A } \\
\hline Intensity & $.94(.84-.92)$ & $.48^{* * *}$ & $-.56 * * *$ & $.65 * * *$ & $.51 * * *$ & $5.6(4.4)$ & $16.2(8.1)$ & $14.1(7.9)$ & $102.07 * * *$ \\
\hline Imagery & $.96(.81-.92)$ & $.48 * * *$ & $-.49 * * *$ & $.59 * * *$ & $.55^{* * *}$ & $11.7(9.8)$ & $28.0(15.1)$ & $29.0(15.1)$ & $73.66 * * *$ \\
\hline Availability & $.97(.92-.93)$ & $.55 * * *$ & $-.54 * * *$ & $.63 * * *$ & $.50 * * *$ & $4.0(3.4)$ & $10.3(5.4)$ & $9.8(5.0)$ & $83.91 * * *$ \\
\hline Total & $.98(.78-.92)$ & $.52 * * *$ & $-.55 * * *$ & $.65 * * *$ & $.55 * * *$ & $21.3(16.6)$ & $54.4(27.0)$ & $52.9(25.4)$ & $94.09 * * *$ \\
\hline \multicolumn{10}{|l|}{ SM-A } \\
\hline Intensity & $.94(.89-.90)$ & $.51 * * *$ & $-.57 * * *$ & $.63 * * *$ & $.62 * * *$ & $6.0(4.6)$ & $16.2(7.8)$ & $16.8(8.7)$ & $105.69 * * *$ \\
\hline Imagery & $.90(.60-.80)$ & $.31 * * *$ & $-.40 * * *$ & $.42 * * *$ & $.48 * * *$ & $24.7(15.7)$ & $36.7(13.3)$ & $39.7(14.4)$ & $36.00 * * *$ \\
\hline Availability & $.92(.86, .86)$ & $.50 * * *$ & $-.44 * * *$ & $.55 * * *$ & $.49 * * *$ & $4.1(3.7)$ & $9.3(5.6)$ & $9.6(5.5)$ & $53.51 * * *$ \\
\hline Total & $.93(.58-.82)$ & $.46^{* * *}$ & $-.52 * * *$ & $.58 * * *$ & $.59 * * *$ & $34.8(20.2)$ & $62.2(22.5)$ & $66.1(24.6)$ & $77.01 * * *$ \\
\hline
\end{tabular}




\section{Author disclosure}

Funding for participant payments was provided by the School of Psychology \& Counselling, QUT. Jason Connor is supported by a National Health and Medical Research Council of Australia Career Development Fellowship (1031909). The authors have no relevant interests to declare. 